\title{
Pengenalan Teknologi Sensor Cahaya untuk Meningkatkan Minat Belajar Siswa Sekolah Dasar
}

\begin{abstract}
Sirojul Hadi ${ }^{1}$, Siti Soraya ${ }^{2}$, Puspita Dewi ${ }^{3}$, Khairan Marzuki ${ }^{4}$, Lalu Ganda Rady Putra ${ }^{5}$, Regina Pricilia Yunika ${ }^{6}$

sirojulhadi@universitasbumigora.ac.id ${ }^{1}$,sitisorayaburhan@universitasbumigora.ac.id ${ }^{2}$, puspitadewi@universitasbumigora.ac.id ${ }^{3}$, khairan.marzuki@universitasbumigora.ac.id $^{2}$ , laluganda@universitasbumigora.ac.id ${ }^{5}$, reginapricilia@universitasbumigora.ac.id ${ }^{6}$
\end{abstract}

1,2,3,4,5,6Universitas Bumigora

\begin{tabular}{ll}
\hline Article History: & Abstract: \\
Received: & Education is an effort to build a better human civilization \\
Revised: & and eliminate human suffering caused by ignorance and \\
Accepted: & underdevelopment in science and technology. In this \\
& research, a workshop was held to introduce light sensor \\
& technology to enhance elementary students' interest in \\
& learning about technology. This research was conducted at \\
& SDN 3 Mataram. The research was carried out by dividing \\
& 40 participants into 5 groups with each group guided by one \\
& mentor. Each group will be guided by a mentor to practice \\
& making light sensor technology until the light sensor circuit \\
& to turn on the lights can function properly. To find out \\
& students' interest in learning is done by making a \\
Keywords: & questionnaire before and after doing the practice. The \\
Light sensor technology, & results obtained from the questionnaire that there is no \\
Interest in Learning, & significant difference between the understanding at the pre- \\
elementary school students & test and post test \\
\hline
\end{tabular}

\section{Pendahuluan}

Tujuan dari Pendidikan di Indonesia yaitu tercantum dalam pembukaan Undang-Undang Dasar 1945 pada alenia ke empat yaitu "memajukan kesejahteraan umum, mencerdaskan kehidupan bangsa, dan ikut melaksanakan ketertiban dunia". Pendidikan merupakan sebuah upaya untuk membentuk peradaban manusia yang lebih baik dengan membantu dan membimbing peserta didik dalam belajar dan mengembangkan bakat yang dimilikinya.

Pendidikan adalah sebuah proses belajar yang berkelanjutan dan berkesinambungan (Sujana, 2019). Sedangkan fungsi dari Pendidikan yaitu menghilangkan penderitaan manusia yang disebabkan oleh kebodohan dan ketertinggalan dalam ilmu pengetahuan dan teknologi. Sistem Pendidikan di Indonesia telah di atur dalam Undang-Undang no. 20 Tahun 2003. Pada pasal 1 disebutkan dalam proses pembelajaran diharapkan peserta didik secara aktif mengembangkan segala potensi yang dimilikinya sehingga dapat memiliki kecerdasan, kepribadian, kekuatan spiritual keagamaan, akhlak mulia dan keterampilan. Sedangkan pada pasal 4 juga dijelaskan bahwa peserta didik dapat mengembangkan potensi diri melalui proses belajar yang tersedia pada jenjang, jalur, dan jenis Pendidikan tertentu. Fase yang sangat menentukan kepribadian peserta didik kedepannya berada pada jenjang Pendidikan sekolah dasar. 
Pada jenjang anak usia sekolah dasar memiliki perkembangan fisik dan mental yang sangat drastis. Usia anak sekolah dasar memiliki rentang usia berkisar antara 6-12 tahun (Sugiyanto, n.d.). Menurut Seifert dan Haffung (Sugiyanto, n.d.) ada tiga jenis perkembangan yang di alami oleh anak usia sekolah dasar yaitu pertama perkembangan fisik seperti otak, otot dan tulang, kedua perkembangan kognitif seperti perkembangan pola pikir anak, ketiga perkembangan psikososial seperti perubahan dan perkembangan emosi pada anak. Untuk merangsang perkembangan pola pikir anak usia sekolah dasar maka perlu diperkenalkan teknologi di masa perkembangan tersebut.

Pada penelitian ini akan diperkenalkan teknologi rangkaian sensor cahaya yang digunakan untuk mengaktifkan dan menonaktifkan lampu. Objek dari penelitian ini yaitu siswa kelas 6 di Sekolah Dasar Negeri 3 Mataram dengan jumlah siswa 40 peserta. Dari keseluruhan siswa dibentuk kelompok menjadi 5 kelompok dengan masing masing kelompok beranggotakan 8 siswa. Masing-masing kelompok ditugaskan untuk membangun sebuah rangkaian sensor cahaya untuk mengkatifkan dan menonaktifkan lampu. Untuk mengetahui minat belajar siswa maka siswa ditugaskan untuk mengisi kuisioner pada sebelum dan sesudah membangun rangkaian sensor cahaya.

\section{Metode Pelaksanaan}

\section{Perancangan Sensor Cahaya}

\section{Sensor LDR}

Sensor yang digunakan untuk mengukur intensitas cahaya yaitu sensor Light Dependent Resistor (LDR). Sensor LDR memiliki keluaran berupa resistansi yang dapat berubah ketika terjadi perbedaan intensitas cahaya yang di tangkap oleh sensor tersebut (Dyah Nur'ainingsih,Radius Iswanton, 2013; Hakim, 2012). Sensor LDR memliki karakteristik yang dapat ditinjau dari segi laju recovery dan respon spectral.

Laju recovery sensor LDR yaitu laju perubahan nilai resistansi dalam selang waktu tertentu (Supatmi, 2010). Bila sensor LDR mengalami perpidahan pada ruangan yang memiliki intensitas cahaya yang rendah maka perubahan resistansi tidak akan langsung terjadi melainkan membutuhkan beberapa waktu tertentu. Laju recovery sensor LDR dapat dituliskan dalam $\mathrm{K} \Omega$ /detik. Perubahan resistansi pada level cahaya 100 lux yaitu $200 \mathrm{~K} \Omega /$ detik selama 20 menit awal (Supatmi, 2010). Perubahan resistansi akan lebih tinggi apabila sensor LDR mengalami perubahan dari intensitas cahaya rendah ke intensitas cahaya yang tinggi. Perubahan resistansi pada level cahaya 400 lux membutuhkan waktu 10 ms untuk mencapai resistansi yang sesuai dengan level cahaya tersebut (Supatmi, 2010).

Laju spectral sensor LDR tidak memiliki sensitivitas yang sama terhadap panjang gelombang cahaya yang di tangkap oleh sensor tersebut. Bahan yang paling banyak digunakan sebagai penghantar arus listrik pada sensor tersebut yaitu tembaga (Supatmi, 2010).

Cara kerja dari sensor LDR yaitu resistansi dari sensor LDR akan mengalami perubahan sesuai dengan intensitas cahaya yang di tangkap oleh sensor tersebut. Ketika sensor LDR menangkap intensitas cahaya yang rendah maka resistansi dari sensor LDR akan semakin tinggi yaitu berada di kisaran $10 \mathrm{M} \Omega$ dan Ketika sensor LDR menangkap intensitas cahaya yang tinggi maka resistansi sensor LDR akan semakin rendah yaitu berada pada kisaran 1 K $\Omega$ (Supatmi, 2010). Bentuk fisik dari sensor LDR dapat ditunjukkan pada gambar 1. 


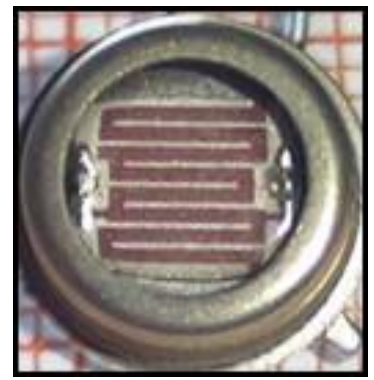

Gambar 1 Bentuk fisik sensor LDR

(Sumber : Sri Supatmi, 2010)

\section{Operational Amplifier LM324N}

Operational amplifier LM324N (Op-Amp LM324N) dapat digunakan sebagai Op-Amp komparator. Op-Amp komparator berfungsi untuk membandingkan tegangan input dan tegangan refrensi dari kaki Op-Amp (Dyah Nur'ainingsih,Radius Iswanton, 2013; Hakim, 2012). Kaki non inverting pada Op-Amp LM324N diberikan masukan tegangan analog yang dihasilkan oleh keluaran rangkaian sensor LDR dan kaki inverting pada Op-Amp diberikan tegangan refrensi. Jika tegangan keluaran sensor lebih besar dibandingkan dengan tegangan refrensi maka keluaran Op-Amp bernilai high dan jika tegangan keluaran sensor lebih kecil dari tegangan refrensi maka keluaran op-amp bernilai low. Konfigurasi pin LM324N dapat ditunjukkan pada gambar 2.

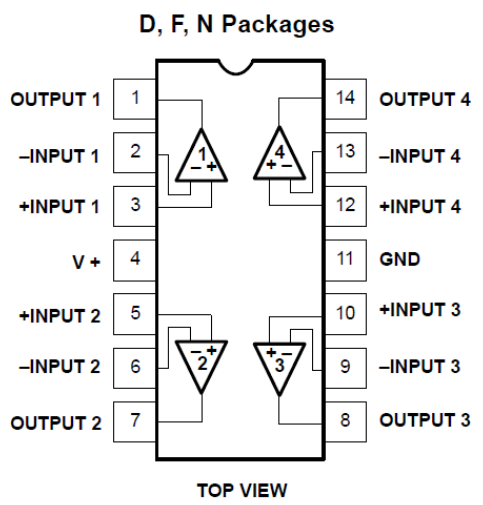

Gambar 2 Konfigurasi pin Operational Amplifier LM324N

(Sumber : https://pdf1.alldatasheet.com/datasheetpdf/view/22756/STMICROELECTRONICS/LM324N.htmI)

\section{Relay 5 Volt DC}

Relay berfungsi sebagai saklar elektronik. Cara kerja dari relay yaitu dengan memanfaatkan elektromagnetik yang disebabkan oleh induksi listrik untuk menggerakkan kontaktor agar terbuka dan tertutup. Desain mekanik dari relay dapat ditunjukkan pada gambar 3. Saat coil pada relay mendapatkan energi listrik maka akan terjadi gaya elektromagnetik. Gaya magnet yang ditimbulkan akan menarik kontaktor berpegas sehingga menyebabkan terhubungnya dua titik kontak. Kontak pada relay dibagai menjadi dua yaitu normally open dan normally close. 


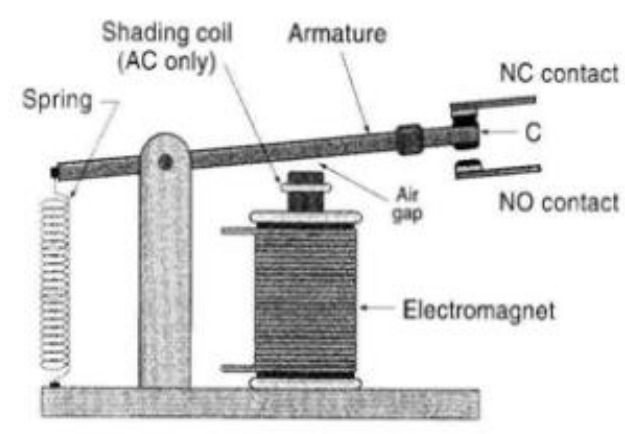

Gambar 3 Desain mekanis relay

(Sumber: https://industri3601.wordpress.com/relay/)

\section{Lampu}

Lampu yang digunakan yaitu lampu dengan tegangan 220 Volt AC dan frekuensi $50 \mathrm{~Hz}-60 \mathrm{~Hz}$. Daya lampu yang digunakan yaitu 7 watt.

\section{Rangkaian Sensor Cahaya}

Rangkaian sensor cahaya yang digunakan untuk mengkatifkan dan menonaktifkan lampu. Rangkaian sensor cahaya dapat ditunjukkan pada gambar 4.

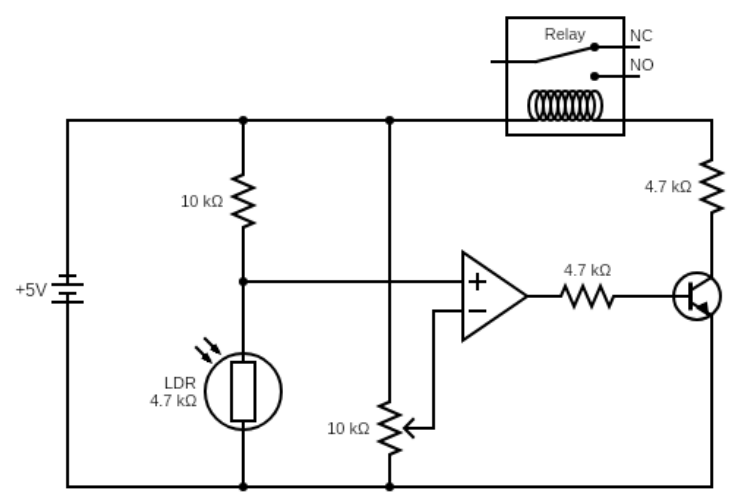

Gambar 4 Rangkaian sensor cahaya untuk mengaktifkan lampu secara otomatis

Pada rangkaian sensor cahaya terdiri dari catu daya DC 5 volt yang berasal dari baterai. Terdapat rangkaian pembagi tegangan dengan salah satu komponennya yaitu sensor LDR. Persamaan rangkaian pembagi tegangan dapat ditunjukkan pada persamaan 1 .

$$
V_{\text {out }}=\frac{R_{L D R}}{R_{(10 K \Omega)}+R_{L D R}} \times V C C
$$

Keluaran pada rangkaian pembagi tegangan akan masuk ke pin non inverting sedangkan keluaran dari resistor variabel akan masuk ke pin inverting pada operational amplifier LM324N. Kedua masukkan tersebut akan dibandingkan tegangannya. Logika dari Op-Amp komparator seperti berikut.

$$
\begin{gathered}
\text { if } V_{\text {out sensor }}>V_{\text {refrence }} \text { than } V_{\text {out } O p \text { Amp }}=V C C \\
\text { if } V_{\text {out sensor }}<V_{\text {refrence }} \text { than } V_{\text {out } O p \text { Amp }}=\text { Ground }
\end{gathered}
$$

Setelah melewati Op-Amp LM324N maka akan melewati transistor TIP31 yang berfungsi 
ADMA

Gurnal Pengabdian dan Pemberdayaan Masyarakat
Vol.1, No.1, June 2020, pp. 33-40

Doi: $x x x x x x x x$

sebagai saklar arus untuk mengaktifkan rangkaian relay. Rangkaian relay berfungsi sebagai saklar tegangan AC/DC yang berfungsi untuk mengaktikan lampu atau menonaktikan lampu.

\section{Hasil}

Pada penelitian ini, untuk mengetahui minat belajar siswa dilakukan dengan cara memberikan kuisioner kepada seluruh peserta. Kuisioner diberikan dalam dua sesi yaitu sesi pertama diberikan sebelum melakukan workshop dan sesi kedua diberikan setelah workshop dilaksanakan. Hasil dari penelitian tersebut dapat ditunjukkan pada tabel 1.

Tabel 1 Data deskriptif tingkat minat belajar siswa SD kelas 6 di SDN 3 Mataram

\section{Q1_Pra}

\begin{tabular}{|ll|r|r|r|r|}
\hline & & & & & Cumulative \\
& & Frequency & Percent & Valid Percent & Percent \\
\hline Valid & laki-laki & 16 & 44.4 & 44.4 & 44.4 \\
& Perempuan & 20 & 55.6 & 55.6 & 100.0 \\
& Total & 36 & 100.0 & 100.0 & \\
\hline
\end{tabular}

Test Statistics

\begin{tabular}{|l|c|c|c|c|c|}
\hline & Q2_Post - & Q3_Post - & Q4_Post - & Q5_Post - & Q6_Post - \\
Q2 Pra & Q3 Pra & Q4 Pra & Q5 Pra & Q6 Pra \\
\hline Z & $-5.292^{\mathrm{a}}$ & $-1.000^{\mathrm{a}}$ & $-5.477^{\mathrm{a}}$ & $.000^{\mathrm{b}}$ & $-.577^{\mathrm{a}}$ \\
Asymp. Sig. (2-tailed) & .000 & .317 & .000 & 1.000 & .564 \\
\hline
\end{tabular}

a. Based on positive ranks.

b. The sum of negative ranks equals the sum of positive ranks.

c. Wilcoxon Signed Ranks Test

Berdasarkan tabel 1 yaitu lebih dari setengah responden dalam penelitian ini adalah perempuan dengan persentase sebesar $55,6 \%$ sedangkan sisanya $44,4 \%$ adalah laki-laki. Terdapat 5 (lima pertanyaan yang diajukan dalam kuesioner dan direspond dalam bentuk pre test dan post test.

Hipotesis yang diajukan adalah pengujian terhadap perbedaan hasil penilaian pada pre test dan post test. Pada pertanyaan pertama disimpulkan adanya perbedaan yang signifikan antara pre test dan post test, begitu juga hasil yang sama pada pertanyaan ketiga. Simpulan ini diperoleh dengan didasari pada nilai Asymp. Sig. yang lebih kecil dari 0,05. Hasil berbeda diperoleh pada pertanyaan kedua, keempat, dan keenam, dimana nilai signifikansi pada ketiga pertanyaan tersebut lebih besar dari 0,05 , sehingga disimpulkan tidak adanya perbedaan yang signifikan antara pemahaman saat pre test dan saat post test. 


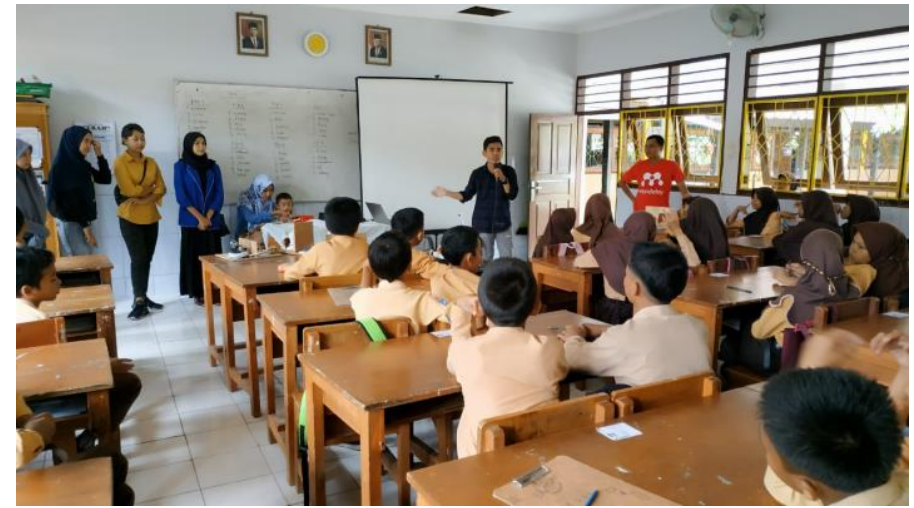

Gambar 5 Menjelaskan ke siswa kelas 6 cara kerja dari teknologi sensor cahaya

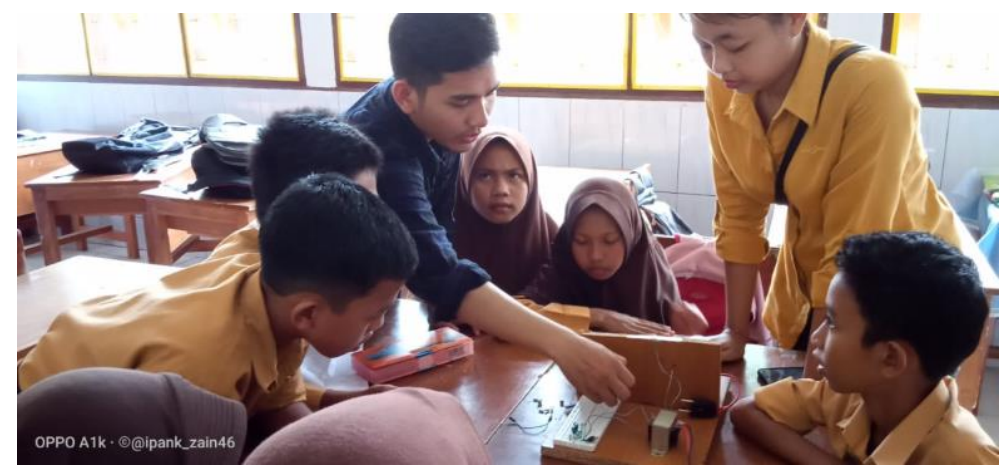

Gambar 6 Mentoring siswa kelas 6 pada saat melakukan praktik merangkai sensor cahaya

\section{Diskusi}

Siswa-siswi kelas 6 di SDN 3 Mataram memiliki antusias yang tinggi ketika mempelajari teknologi sensor cahaya akan tetapi diperlukan waktu yang lebih banyak agar siswa dan siswi dapat memahami secara keseluruhan cara kerja dari sensor cahaya tersebut.

\section{Kesimpulan}

Salah satu upaya untuk meningkatkan minat belajar siswa-siswi sekolah dasar yaitu dengan mengenalkan mereka pada teknologi sehingga kemampuan berpikir dan kreativitas siswasiswi semakin berkembang. Teknologi yang diperkenalkan yaitu teknologi sensor cahaya dengan menggunakan sensor light dependent resistor untuk mengaktifkan dan menonaktifkan lampu dengan daya 7 watt. Peserta pada penelitian ini yaitu kelas 6 di SDN 3 Mataram. Untuk mengetahui minat belajar siswa dilakukan dengan mengisi kuisioner pada saat sebelum praktik dan sesudah praktik. Hasil dari penelitian yaitu tidak adanya perbedaan yang signifikan antara pemahaman saat pre-test dan saat post-test yang disebabkan kurangnya waktu yang diberikan ke siswa-siswa untuk memahami rangkaian sensor cahaya yang dibuat.

\section{Pengakuan/Acknowledgements}

Kami mengucapkan terimakasih kepada Suwartini, S.Pd selaku kepala sekolah SDN 3 Mataram dan M. Zul Irfan Zain, S.Pd selaku guru SDN 3 Mataram yang telah memberikan kesempatan buat kami untuk melakukan pengabdian dan penelitian di SDN 3 Mataram dan 
terimakasih juga kepada siswa-siswi kelas 6 di SDN 3 Mataram yang telah melakukan Kerjasama yang baik dengan kami.

\section{Daftar Pustaka}

Dyah Nur'ainingsih,Radius Iswanton, H. S. (2013). Lampu Taman Otomatis Menggunakan Solar Tracker Berbasis Mikrokontroler At89s51. Volume V(2), 124-131.

Hakim, R. C. M. R. (2012). Sirkulasi Otomatis Pada Kolam Taman Berbasis Mikrokontroler AT89S51. UG JOURNAL, 6(4), 6-8.

https://ejournal.gunadarma.ac.id/index.php/ugjournal/article/viewFile/912/804

Sugiyanto. (n.d.). Karakteristik Anak Usia SD. 1-7. https://doi.org/10.1007/978-1-4614-7990-1

Sujana, I. W. C. (2019). Fungsi Dan Tujuan Pendidikan Indonesia. Adi Widya: Jurnal Pendidikan Dasar, 4(1), 29. https://doi.org/10.25078/aw.v4i1.927

Supatmi, S. (2010). Pengaruh Sensor Ldr Terhadap Pengontrolan Lampu. Majalah IImiah UNIKOM, 8(2), 175-180. http://jurnal.unikom.ac.id/_s/data/jurnal/v08-n02/volume-82-artikel5.pdf/pdf/volume-82-artikel-5.pdf 
